\title{
The distribution of the therapeutic monoclonal antibodies cetuximab and trastuzumab within solid tumors
}

\author{
Carol M Lee and Ian F Tannock*
}

\begin{abstract}
Background: Poor distribution of some anticancer drugs in solid tumors may limit their anti-tumor activity.

Methods: Here we used immunohistochemistry to quantify the distribution of the therapeutic monoclonal antibodies cetuximab and trastuzumab in relation to blood vessels and to regions of hypoxia in human tumor xenografts. The antibodies were injected into mice implanted with human epidermoid carcinoma A431 or human breast carcinoma MDA-MB-231 transfected with ERBB2 (231-H2N) that express high levels of ErbB1 and ErbB2 respectively, or wild-type MDA-MB-231, which expresses intermediate levels of ErbB1 and low levels of ErbB2.
\end{abstract}

Results: The distribution of cetuximab in A431 xenografts and trastuzumab in 231- H2N xenografts was time and dose dependent. At early intervals after injection of $1 \mathrm{mg}$ cetuximab into A431 xenografts, the concentration of cetuximab decreased with increasing distance from blood vessels, but became more uniformly distributed at later times; there remained however limited distribution and binding in hypoxic regions of tumors. Injection of lower doses of cetuximab led to heterogeneous distributions. Similar results were observed with trastuzumab in 231-H2N xenografts. In MDA-MB-231 xenografts, which express lower levels of ErbB1, homogeneity of distribution of cetuximab was achieved more rapidly.

Conclusions: Cetuximab and trastuzumab distribute slowly, but at higher doses achieve a relatively uniform distribution after about 24 hours, most likely due to their long half-lives in the circulation. There remains poor distribution within hypoxic regions of tumors.

\section{Background}

The ErbB family of receptor kinases is a group of four trans-membrane proteins (ErbB1 - ErbB4) that share similarities in structure and are involved in signaling pathways that stimulate cellular proliferation [1]. Ligand binding induces receptor homo- and hetero-dimerization, although no ligand has been identified for ErbB2. Dimerization of the receptors stimulates their intrinsic tyrosine kinase activity resulting in receptor autophosphorylation [2]. These phosphorylated residues serve as binding sites for molecules involved in the regulation of intracellular signaling cascades. Overexpression of ErbB receptors may occur in a wide range of epithelial cancers,

\footnotetext{
*Correspondence: ian.tannock@uhn.on.ca

${ }^{1}$ Divisions of Applied Molecular Oncology and Medical Oncology and Hematology Princess Margaret Hospital and University of Toronto, Toronto, ON, Canada

Full list of author information is available at the end of the article
}

including those of the breast [3], colon [4], head and neck [5], kidney [6], lung [7,8], pancreas [9], prostate [10] and esophagus [11,12] and has been associated with an aggressive phenotype.

Molecular targeted agents that interact with receptor tyrosine kinases on tumor cells are used increasingly in clinical oncology. There are two classes of agents, monoclonal antibodies and low-molecular-weight tyrosine kinase inhibitors. Cetuximab (chimeric mouse/human) and trastuzumab (humanized) are monoclonal antibodies that target the extracellular domain of the receptors ErbB1 [13-16] and ErbB2 [15,17] respectively. Binding of cetuximab and trastuzumab to ErbB1 and ErbB2 respectively prevents receptor phosphorylation and activation of the kinase domain, thereby inhibiting cell proliferation [18-20]. Binding of trastuzumab to its receptor also reduces shedding of the extracellular domain of ErbB2 
and prevents the production of an active truncated fragment [20-22]. These agents have shown therapeutic activity against colorectal cancer and breast cancer respectively and are in wide clinical use [21,22].

Limited penetration of drugs through tumor tissue is an important and rather neglected cause of clinical resistance to chemotherapy [23-25]. Drug distribution from blood vessels within tumors depends on diffusion and and/or convection, and is inhibited by consumption in proximal cells [23,25-27]; for monoclonal antibodies consumption is due to binding to the receptor target, which is dependent on antibody dose, number of antigenic targets per cell, and the affinity of the antibody for its target [28]. Convection depends on gradients of pressure (both hydrostatic and osmotic) between the vascular space and the interstitial space, while diffusion depends on molecular size, shape and concentration gradients [26,27]. Because monoclonal antibodies are large molecules they might be expected to have poor distribution from tumor blood vessels [28]. However drugs with a long half-life in the circulation may establish a more uniform distribution in tissues even if penetration of tissue is relatively slow, whereas drugs with a short half-life may have a non-uniform distribution. Here we report a study of the distribution of the monoclonal antibodies, cetuximab and trastuzumab, in tumors that express different levels of their target receptors.

\section{Methods}

\section{Drugs and reagents}

The monoclonal antibody cetuximab (IMC-C225, Erbitux) was provided by Imclone Systems, Inc. (New York, NY, USA) as a solution at a concentration of $2 \mathrm{mg} /$ $\mathrm{ml}$. Trastuzumab (Herceptin) was obtained from the hospital pharmacy at a concentration of $21 \mathrm{mg} / \mathrm{ml}$. The hypoxia-selective agent EF5 and Cy5-conjugated anti-EF5 antibody $[29,30]$ were kindly provided by Dr. C. Koch, Philadelphia, PA. Blood vessels in tumor sections were visualized with a rat anti-mouse CD31 (PECAM-1) monoclonal antibody that was purchased from BD Pharmingen (Mississauga, ON, Canada) and the Cy3conjugated goat anti-rat IgG secondary antibody was purchased from Jackson Immuno Research Laboratories, Inc. (West Grove, PA). Cetuximab and trastuzumab were recognized in tissue sections with goat anti-human IgG conjugated with horseradish peroxidase (Biosource, Montreal, Canada).

\section{Cell lines and tumor models}

Experiments were performed utilizing the ErbB1-overexpressing human epidermoid carcinoma (A431) and a human breast adenocarcinoma (MDA-MB-231), using both wild-type and ERBB2 transfected (231-H2N) cell lines. A431 and MDA-MB-231 cells were obtained from the American Type Culture Collection (Manassas, VA, USA), while MDA-MB-231 cells transfected with ERBB2 (231-H2N) were kindly provided by Dr. J. Medin [31] (University of Toronto, ON, Canada). All the cell lines were maintained as monolayers in Dulbecco's Modified Eagle's Medium (DMEM), supplemented with 10\% fetal calf serum (FCS), at $37^{\circ} \mathrm{C}$ in a humidified atmosphere of 95\% air plus $5 \% \mathrm{CO}_{2}$. Tests were performed routinely to ensure that cells were free of mycoplasma. Tumors were generated by injection of $\sim 2 \times 10^{6}$ exponentially-growing cells into the right and left flanks of 6-8 week old female athymic nude mice, purchased from Harlan SpragueDawley Laboratory Animal Centre (Madison, WI, USA). Mice were housed five per cage, and sterile tap water and food were given ad libitum. All procedures were carried out following approval of the Institutional Animal Care Committee.

Expression of ErbB1 and ErbB2 receptors in the xenografts was confirmed by applying cetuximab or trastuzumab to sections of tumors ex vivo, followed by their recognition using anti-human IgG as described below. Endogenous expression of ErbB1 and ErbB2 were also confirmed and assessed by diagnostic antibodies from Zymed (Clone 31G7) and Neomarkers (Clone SP3) respectively.

\section{Experimental design}

Tumor-bearing mice were divided randomly into groups of 5-6, and treatment with cetuximab or trastuzumab was initiated when the diameter of tumors was approximately 7-8 mm. One group was selected randomly as the control, and the other mice received cetuximab or trastuzumab (0.01 $\mathrm{mg}$ to $1.0 \mathrm{mg}$ ) as a single intraperitoneal (i.p.) or intravenous (i.v.) injection. Control mice were given equal volumes of PBS. Animals were killed at various intervals after injection of cetuximab or trastuzumab; they received an i.p. injection of EF5 (0.2 $\mathrm{ml}$ of $10 \mathrm{mM}$ EF5) 2 hours before they were killed in order to identify hypoxic regions of tumors [29,30]. Tumors were removed and embedded with Tissue-Tek OCT (Optimal Cutting Temperature, Sakura Finetek USA Inc., Torrance, CA). The tissue boxes were gently immersed in liquid nitrogen, and then stored at $-70^{\circ} \mathrm{C}$.

Cryosections were prepared at $10 \mu \mathrm{m}$ thickness and triple stained to identify cetuximab or trastuzumab, CD31 and EF5. Horseradish peroxidase (HRP) conjugated to anti-human IgG was used to recognize the therapeutic monoclonal antibodies. DAB (3,3'-diaminobenzidine) is a chromogenic substrate for HRP and it deposits a brown specific stain in the presence of HRP. Blood vessels in tissue sections were recognized by the expression of CD31 on endothelial cells. Purified rat anti-mouse CD31 monoclonal antibody was applied at a concentration of 1:500 and left overnight at $4^{\circ} \mathrm{C}$. Primary antibody binding was 
disclosed using a Cy3-conjugated goat anti-rat IgG secondary antibody. Hypoxic regions were recognized by cyanine-5-conjugated mouse anti-EF5 (1/50) antibody.

\section{Fluorescence microscopy}

Images were tiled using an Olympus BX50 upright fluorescent microscope linked to a Photometrics CoolSnap HQ2 CCD camera, a motorized X-Y stage connected to a computer preloaded with Media Cybernetics In Vivo and Image Pro-PLUS software (Media Cybernetics, Silver Spring, MD) and a stage controller board. Tumor sections were scanned and tiled under white light and two different filters: (i) images of Cy3 fluorescence of CD31 were visualized using $530 \mathrm{~nm}$ to $560 \mathrm{~nm}$ excitation and $573 \mathrm{~nm}$ to $647 \mathrm{~nm}$ emission filter sets, while (ii) images of the Cy5 fluorescence of EF5 were visualized with $630 \mathrm{~nm}$ to 650 $\mathrm{nm}$ excitation and $665 \mathrm{~nm}$ to $695 \mathrm{~nm}$ emission filter sets. Composite images of cetuximab, CD31, and EF5 or trastuzumab, CD31 and EF5 were generated using Image Pro PLUS (version 5) and subsequently pseudo-colored. To investigate the distribution of drug in relation to distance from the nearest blood vessel or hypoxic region, images displaying anti-CD31 staining or EF5 staining were converted to black and white binary images: each image was overlayed with the corresponding field of view displaying drug intensity, resulting in an 8-bit black and white image with blood vessels or hypoxic regions identified by an intensity of 255 (white) and drug intensity ranging from 0-254 (gray scale). Areas of interest were selected from each tissue section and were on average $1600 \times 1600 \mu \mathrm{m}$ $\left(0.4 \mu^{2} /\right.$ pixel). Areas of necrosis and staining artifact were excluded.

Distributions of each monoclonal antibody in relation to distance from the nearest blood vessel and the nearest region of hypoxia in the tumor section were quantified utilizing Image Pro software. A minimum signal level just below threshold was set for each tissue section; this was based on an average background reading from regions without staining. The pixel intensity and distance to the nearest vessel or region of hypoxia for all pixels within the selected region of interest above threshold were measured with a customized algorithm. The intensity of cetuximab or trastuzumab signal was represented as mean \pm SEM for all pixels at a given distance to the nearest vessel or region of hypoxia and plotted as a function of that distance.

\section{Results}

\section{Expression of ErbB receptors}

Ex vivo staining using cetuximab was used to recognize expression of ErbB1 in A431 and MDA-MB-231 tumor sections; these tumors express high and intermediate levels of ErbB1 respectively (Fig. 1, upper panels). Similarly, ex vivo application of trastuzumab indicates low expres-

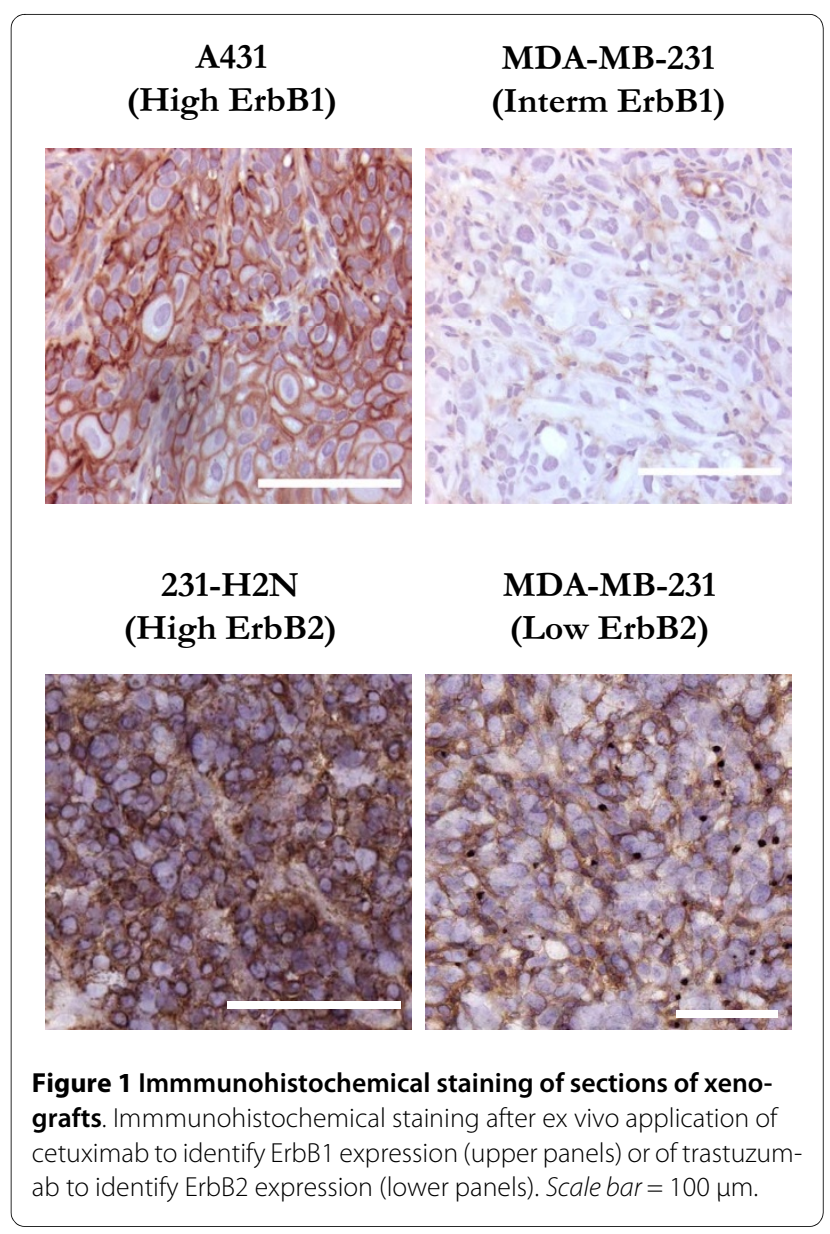

sion of ErbB2 in wild-type MDA-MB-231 xenografts and high expression in the ERBB2-transfected $231-\mathrm{H} 2 \mathrm{~N}$ xenografts (Fig. 1, lower panels). In tumors that express the receptors the staining indicates their distribution on the cell membrane.

Expression of receptors was fairly uniform in tumors, except for regions of hypoxia (defined by EF5 staining) where there was lower expression of ErbB1 and ErbB2. We also studied receptor expression in tumors of animals that were treated with the therapeutic antibodies, and found no effect of treatment on receptor expression.

\section{Time- and dose-dependent distribution of cetuximab}

Dose-dependent distribution of cetuximab in A431 xenografts $24 \mathrm{~h}$ after i.p. injection of different doses is shown in Fig. 2. After injection of $0.01 \mathrm{mg}$ or $0.05 \mathrm{mg}$ cetuximab, there was selective distribution closer to blood vessels, and no penetration to hypoxic regions (shown in green), but at $24 \mathrm{~h}$ after injection of $1.0 \mathrm{mg}$ cetuximab, the distribution was more uniform within the tumor, although there remained minimal drug penetration to hypoxic regions identified by uptake of EF5. Staining was honeycomb in appearance, consistent with antibody binding to receptors on the outer membranes of tumor cells. There 

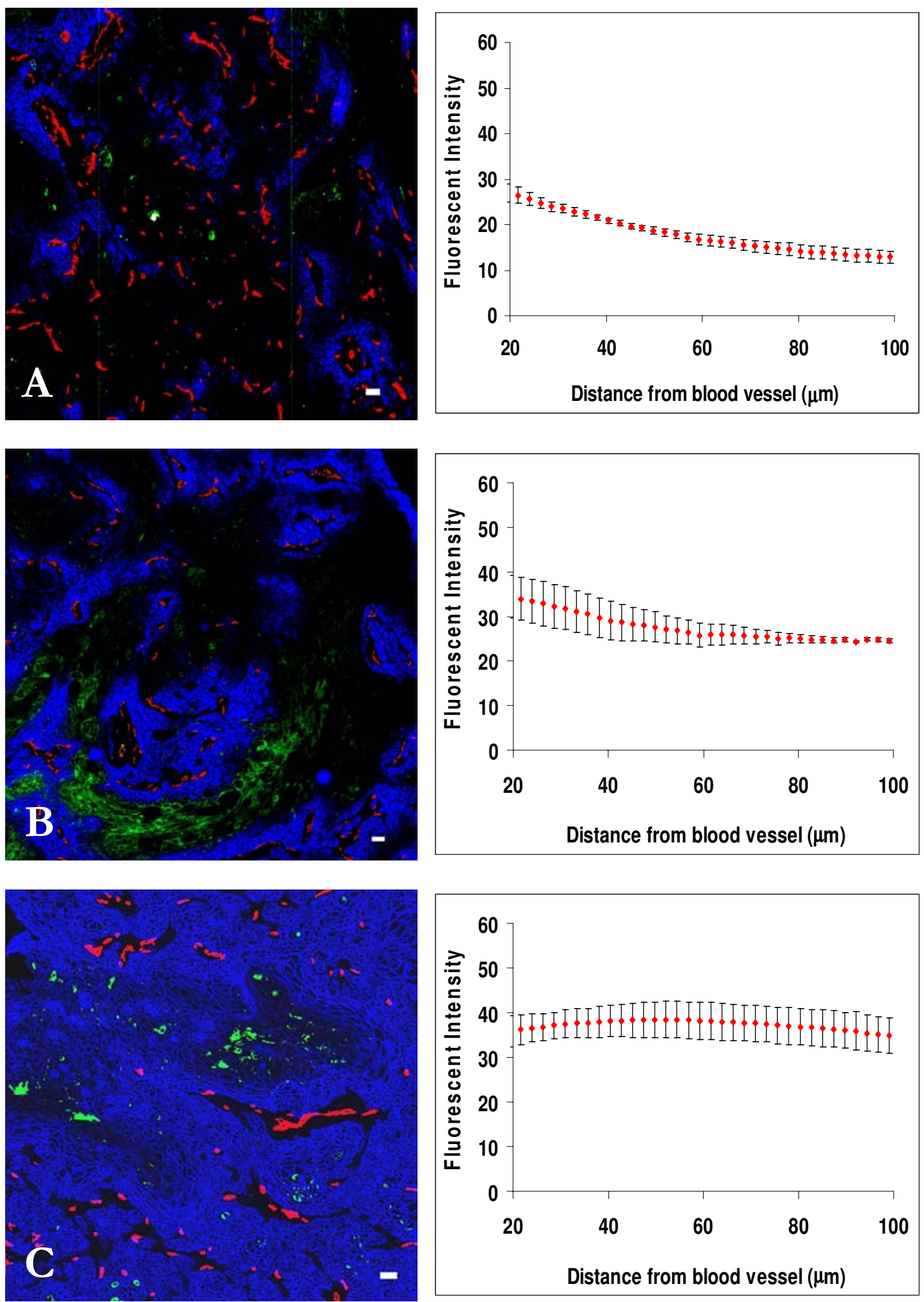

Figure 2 Dose response distribution of cetuximab in relation to blood vessels and regions of hypoxia in A431 xenografts. Left panels show the distribution of cetuximab (blue) in relation to blood vessels (red) and regions of hypoxia (green) in A431 xenografts at $24 \mathrm{~h}$ after an i.p. injection of (A) $0.01 \mathrm{mg}$, (B) $0.05 \mathrm{mg}$, and (C) $1.0 \mathrm{mg}$. In right panels staining intensity (mean +/- SEM) due to cetuximab is plotted against distance from the nearest blood vessel in the tumor section. Note minimal drug binding in hypoxic regions. Scale bar $=100 \mu \mathrm{m}$. 
was an apparent increase in intensity at very short distances from the centers of blood vessels, likely because of lack of expression of ErbB1 on endothelial cells and pericytes.

The time-dependent distribution of cetuximab after an i.p. injection of $1.0 \mathrm{mg}$ into mice bearing A431 xenografts is shown in Fig 3. With exclusion of the immediate perivascular region, there was a gradient of decreasing concentration at increasing distances from blood vessels at $30 \mathrm{~min}$ and $4 \mathrm{~h}$ after injection (Fig 3), but at $24 \mathrm{~h}$ and 48 $\mathrm{h}$ the intensity of cetuximab staining was relatively uniform within the tumor tissue (Figs. 2 and 3). There was no staining due to cetuximab in hypoxic regions shown in green. Cetuximab distribution in relation to hypoxic regions is also plotted in Fig 3, which shows that staining intensity due to cetuximab increases as the distance from the hypoxic regions increases. The slopes of the relationships between staining intensity of cetuximab and distance from blood vessels after various doses and times are summarized in Table 1 . These data confirm relatively uniform distribution at $24 \mathrm{~h}-48 \mathrm{~h}$ after injection of the higher dose of $1 \mathrm{mg}$ cetuximab, with the caveat that there is still minimal binding within hypoxic regions of the tumors.

The distribution of cetuximab $24 \mathrm{~h}$ after an intravenous injection of different doses was also investigated in A431 xenografts (data not shown). There were no significant differences in the distributions of cetuximab after i.p. and i.v. injection.

Time- and dose-dependent distribution of cetuximab in MDA-MB-231 xenografts (which express intermediate levels of ErbB1) is summarized in Table 1: with exclusion of the immediate perivascular region, staining intensity was relatively constant with increasing distance from the blood vessel at most times and doses, suggesting more rapid distribution than in the A431 tumors, which have higher levels of expression of ErbB1. Absolute levels of bound cetuximab increased with both dose injected and time after injection.

\section{Time- and dose-dependent distribution of trastuzumab}

The distribution of trastuzumab at $2 \mathrm{~h}$ after i.v. injection of doses of $0.1 \mathrm{mg}, 0.3 \mathrm{mg}$ or $1.0 \mathrm{mg}$ into mice bearing 231-H2N xenografts (which over-express ErbB2) is shown in Fig 4. There was selective localization close to blood vessels at lower doses and uniform distribution after the $1.0 \mathrm{mg}$ dose. Staining due to trastuzumab was not found in regions of hypoxia (shown in green). Staining intensities at $\sim 20 \mu \mathrm{m}$ from blood vessels varied by a factor of $\sim 1.5$ after i.v. injection of doses of $0.1 \mathrm{mg}-1.0$ mg (Table 1), suggesting that binding to proximal cells is close to saturated.

The distribution of trastuzumab as a function of time after injection of $0.3 \mathrm{mg}$ is shown in Fig 5: There was selective perivascular localization of trastuzumab at 30 min and $4 \mathrm{~h}$ after injection, but more uniform distribution after $24 \mathrm{~h}$. Staining intensities at $\sim 20 \mu \mathrm{m}$ from blood vessels after an injection of $0.3 \mathrm{mg}$ of trastuzumab varied only by a factor of $\sim 1.5$ at $30 \mathrm{~min}$ to $24 \mathrm{~h}$ after injection, again suggesting early saturation of cells proximal to blood vessels. Trastuzumab distribution in relation to hypoxic regions is plotted in green in Fig 5, staining intensity due to trastuzumab increases in regions close to hypoxia as the time interval increases.

Trastuzumab was not found bound to cells of MDAMB-231 xenografts which express low levels of ErbB2.

\section{Discussion}

Cetuximab and trastuzumab have shown limited efficacy in causing remission in a proportion of patients with metastatic colorectal cancer and breast cancer respectively $[21,22]$, while trastuzumab has improved survival of women with ErbB2 positive breast cancer when given as adjuvant therapy after chemotherapy [32-34]. Monoclonal antibodies are large molecules, which are "consumed" by binding to receptors on the cell surface, conditions that might lead to poor penetration of tissue within solid tumors [28]. Indeed, an early study of the distribution of a radiolabeled monoclonal antibody into multicellular spheroids suggested very slow penetration of tissue, with establishment of a steep concentration gradient [35], and more recent studies of the penetration of drugs such as doxorubicin (which binds avidly to DNA) have shown quite poor distribution [23-25]. Thus limited distribution of therapeutic agents within solid tumors is a potentially important and relatively neglected cause of drug resistance, especially in the metastatic setting. Here we have used quantitative immunohistochemistry to study the distribution within human tumor xenografts of two therapeutic monoclonal antibodies in clinical use, cetuximab and trastuzumab, to determine if their efficacy might be limited by failure to reach all of the target tumor cells in an effective concentration.

The results of our study show that distribution of both of these therapeutic antibodies is time and dose-dependent. At short intervals after injection of all doses there is a concentration gradient of staining intensity of the antibodies with increasing distance from blood vessels within tumors that strongly express the target receptor. However there is a greater change in the gradient of cetuximab intensity in A431 xenografts than of trastuzumab intensity in 231-H2N xenografts. At moderate and high doses the distribution then becomes more uniform with time, while at lower doses the heterogeneous distribution is retained. Distribution of cetuximab and trastuzumab in relation to hypoxic regions provides a better understanding of the distribution of the antibodies distal to blood vessels. There remains minimal drug distribution to 
Table 1: Cetuximab and trastuzumab staining intensity in different xenografts.

\begin{tabular}{|c|c|c|c|c|c|c|}
\hline Cell line & $\begin{array}{l}\text { Monoclonal } \\
\text { antibody }\end{array}$ & Dose (mg) & $\begin{array}{l}\text { Time after } \\
\text { injection }\end{array}$ & $\begin{array}{c}\text { Staining Intensity at } \\
20 \mu \mathrm{m} \text { from blood } \\
\text { vessels (mean IU) } \pm \text { SEM }\end{array}$ & $\begin{array}{c}\text { Staining Intensity at } 100 \\
\mu \mathrm{m} \text { from blood vessels } \\
\text { (mean IU) } \pm \text { SEM }\end{array}$ & $\begin{array}{c}\text { Gradient of } \\
\text { Staining } \\
\text { Intensity }(\mathrm{IU} / \mu \mathrm{m})\end{array}$ \\
\hline \multirow[t]{6}{*}{ A431 } & Cetuximab & 0.01 & $24 \mathrm{~h}$ & $26.8 \pm 2.0$ & $12.7 \pm 1.4$ & -0.18 \\
\hline & & 0.05 & $24 \mathrm{~h}$ & $34.3 \pm 4.8$ & $24.5 \pm 0.4$ & -0.12 \\
\hline & & 1.0 & $30 \mathrm{~min}$ & $36.1 \pm 0.2$ & $21.2 \pm 1.3$ & -0.19 \\
\hline & & 1.0 & $4 \mathrm{~h}$ & $34.9 \pm 2.7$ & $25.0 \pm 2.3$ & -0.12 \\
\hline & & 1.0 & $24 \mathrm{~h}$ & $35.9 \pm 3.5$ & $34.7 \pm 3.9$ & -0.02 \\
\hline & & 1.0 & $48 \mathrm{~h}$ & $36.1 \pm 1.2$ & $37.8 \pm 1.8$ & -0.02 \\
\hline \multirow[t]{11}{*}{ MDA-MB-231 } & Cetuximab & 0.01 & $24 \mathrm{~h}$ & $7.0 \pm 0.6$ & $7.4 \pm 1.1$ & 0.01 \\
\hline & & 0.05 & $24 \mathrm{~h}$ & $7.6 \pm 0.8$ & $6.9 \pm 0.9$ & -0.01 \\
\hline & & 0.1 & $24 \mathrm{~h}$ & $15.0 \pm 2.8$ & $18.5 \pm 2.8$ & 0.04 \\
\hline & & 0.5 & $15 \mathrm{~min}$ & $6.9 \pm 1.5$ & $6.3 \pm 0.7$ & -0.01 \\
\hline & & 0.5 & $30 \mathrm{~min}$ & $8.3 \pm 5.7$ & $5.7 \pm 3.7$ & -0.03 \\
\hline & & 0.5 & $1 \mathrm{~h}$ & $18.9 \pm 1.1$ & $17.0 \pm 1.1$ & -0.02 \\
\hline & & 0.5 & $2 \mathrm{~h}$ & $19.1 \pm 3.9$ & $14.0 \pm 2.9$ & -0.06 \\
\hline & & 0.5 & $4 \mathrm{~h}$ & $20.8 \pm 1.5$ & $24.3 \pm 1.5$ & 0.04 \\
\hline & & 0.5 & $6 \mathrm{~h}$ & $17.6 \pm 4.0$ & $20.3 \pm 4.6$ & 0.03 \\
\hline & & 0.5 & $24 \mathrm{~h}$ & $16.7 \pm 2.2$ & $20.7 \pm 1.6$ & 0.05 \\
\hline & & 1.0 & $24 \mathrm{~h}$ & $17.3 \pm 2.7$ & $21.2 \pm 2.5$ & 0.05 \\
\hline \multirow[t]{6}{*}{$231-\mathrm{H} 2 \mathrm{~N}$} & Trastuzumab & 0.1 & $2 \mathrm{~h}$ & $16.8 \pm 2.1$ & $12.7 \pm 1.8$ & -0.05 \\
\hline & & 0.3 & $30 \mathrm{~min}$ & $19.4 \pm 0.9$ & $16.6 \pm 1.3$ & -0.04 \\
\hline & & 0.3 & $2 \mathrm{~h}$ & $23.0 \pm 1.6$ & $19.9 \pm 2.1$ & -0.04 \\
\hline & & 0.3 & $4 \mathrm{~h}$ & $24.0 \pm 2.1$ & $18.5 \pm 3.0$ & -0.07 \\
\hline & & 0.3 & $24 \mathrm{~h}$ & $29.0 \pm 1.0$ & $27.3 \pm 0.8$ & -0.02 \\
\hline & & 1.0 & $2 \mathrm{~h}$ & $27.0 \pm 1.3$ & $26.2 \pm 1.4$ & -0.01 \\
\hline
\end{tabular}

Staining intensity of cetuximab and trastuzumab at $20 \mu \mathrm{m}$ and $100 \mu \mathrm{m}$ from blood vessels in A431, MDA-MB-231 and 231-H2N xenografts. Gradient of staining intensity is shown.

hypoxic tumor cells under all conditions, which is probably due both to limited availability of drug in these regions, and to decreased expression of the ErbB receptors under hypoxic conditions.

The difference in time dependence of the distributions of the monoclonal antibodies as compared to that for doxorubicin, which is relatively independent of time after injection [24] is most likely due to the half-lives of the drugs in the circulation: doxorubicin has a short initial half-life [36], such that most penetration from vessels takes place quickly, whereas monoclonal antibodies have a half-life of days [37-39], allowing for a more constant process of tissue penetration.

The gradients of cetuximab intensity in MDA-MB-231 xenografts, which express intermediate levels of ErbB1, are less steep than in A431 xenografts, which express higher levels of ErbB1, and homogeneity of distribution of cetuximab in MDA-MB-231 xenografts was achieved more rapidly. This is probably due to the low receptor binding of cetuximab (i.e. less consumption of drug) by proximal cells in MDA-MB-231 xenografts. Trastuzumab was not identified after injection in MDA-MB-231 xenografts, which express low levels of ErbB2.

Multiple phase I and II clinical trials have established that standard weekly dosing of cetuximab or trastuzumab in humans achieves trough serum concentrations that are usually above $50 \mu \mathrm{g} / \mathrm{ml}[37,38,40-42]$. We did not measure serum concentration of cetuximab or trastuzumab in our mice. Others have reported maximum serum levels of cetuximab of $\sim 65 \mu \mathrm{g} / \mathrm{ml}$ and $\sim 400 \mu \mathrm{g} / \mathrm{ml}$ cetuximab after injection of doses of $0.25 \mathrm{mg}$ and $1.0 \mathrm{mg}$ into mice respectively $[28,39]$, similar to those reported in patients. Injec- 

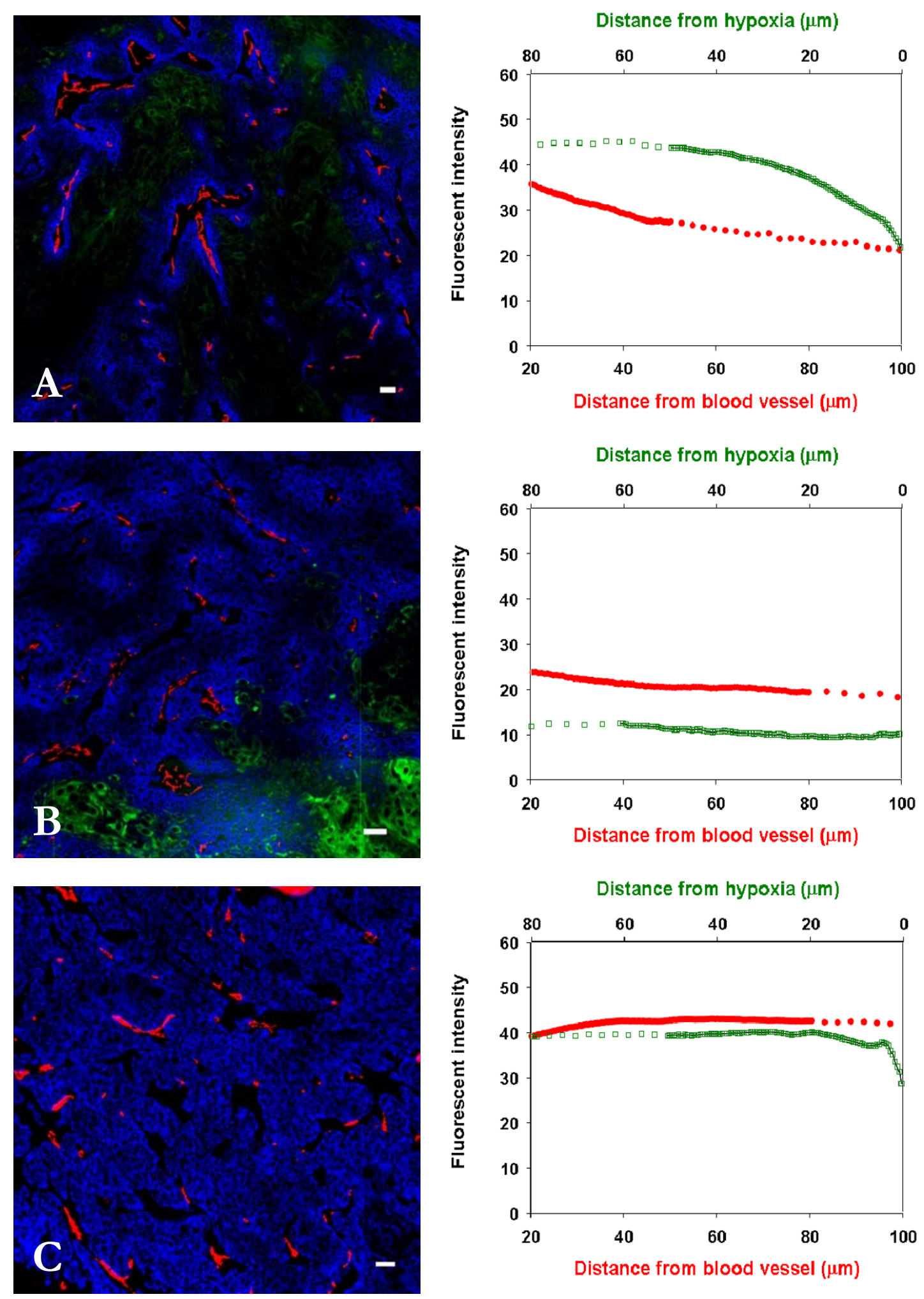

Figure 3 Time response distribution of cetuximab in relation to blood vessels and regions of hypoxia in A431 xenografts. Left panels show the distribution of cetuximab (blue) in relation to blood vessels (red) and regions of hypoxia (green) in A431 xenografts at (A) $30 \mathrm{~min}$, (B) $4 \mathrm{~h}$ and (C) $48 \mathrm{~h}$ after i.p. injection of $1.0 \mathrm{mg}$. In right panels staining intensity due to cetuximab is plotted against distance to the blood vessel in red and distance to region of hypoxia in green. Scale bar $=100 \mu \mathrm{m}$. 

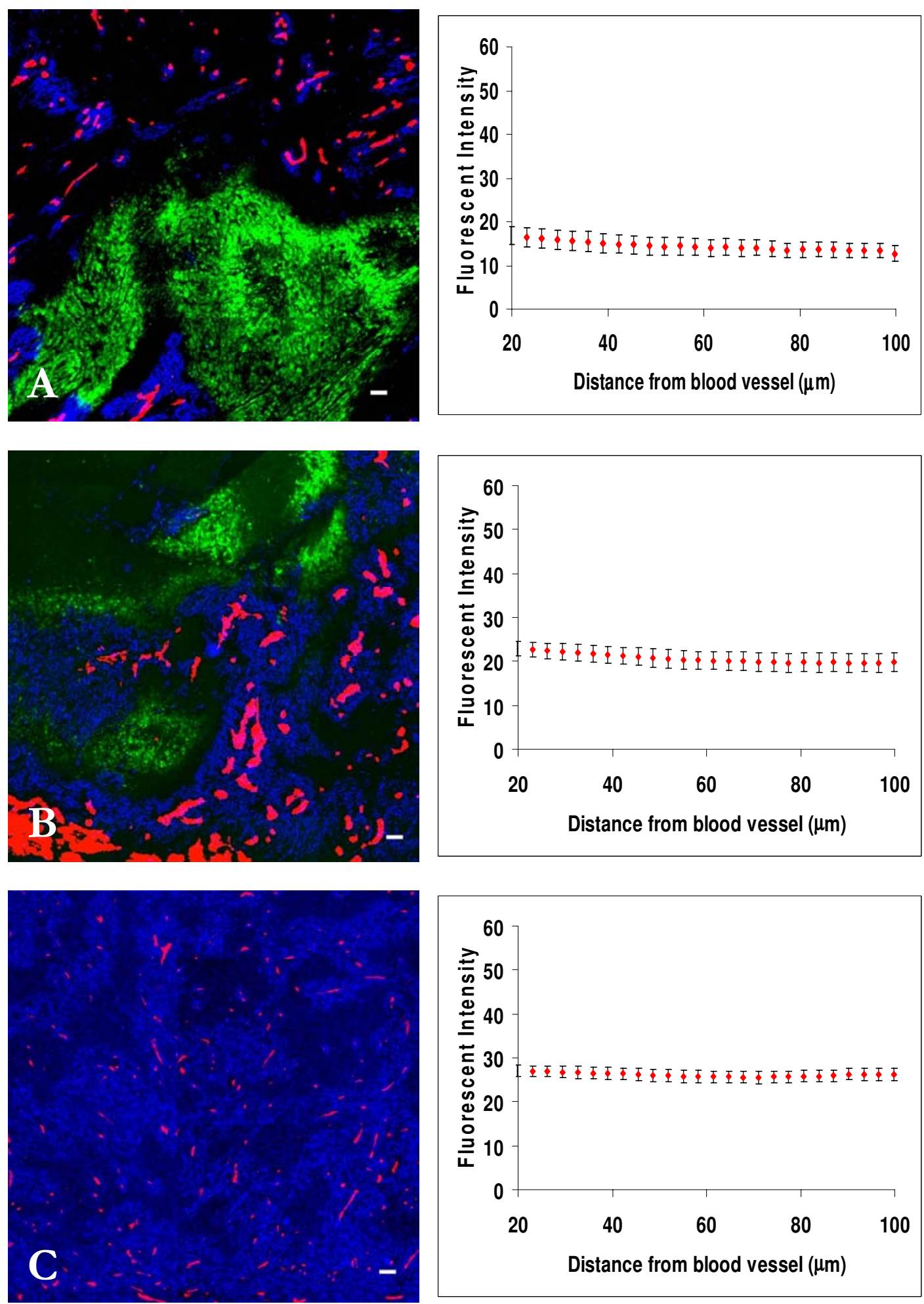

Figure 4 Dose response distribution of trastuzumab in relation to blood vessels and regions of hypoxia in 231-H2N xenografts. Left panels show the distribution of trastuzumab (blue) in relation to blood vessels (red) and regions of hypoxia (green) in MDA-MB-231 breast cancer xenografts transfected with ErbB2 (231-H2N) at $2 \mathrm{~h}$ after i.v. injection of (A) $0.1 \mathrm{mg}$, (B) $0.3 \mathrm{mg}$ and (C) $1.0 \mathrm{mg}$. In right panels staining intensity (mean +/- SEM) due to trastuzumab is plotted against distance from the nearest blood vessel in the tumor section. Note minimal drug binding in hypoxic regions. Scale bar $=100 \mu \mathrm{m}$. 

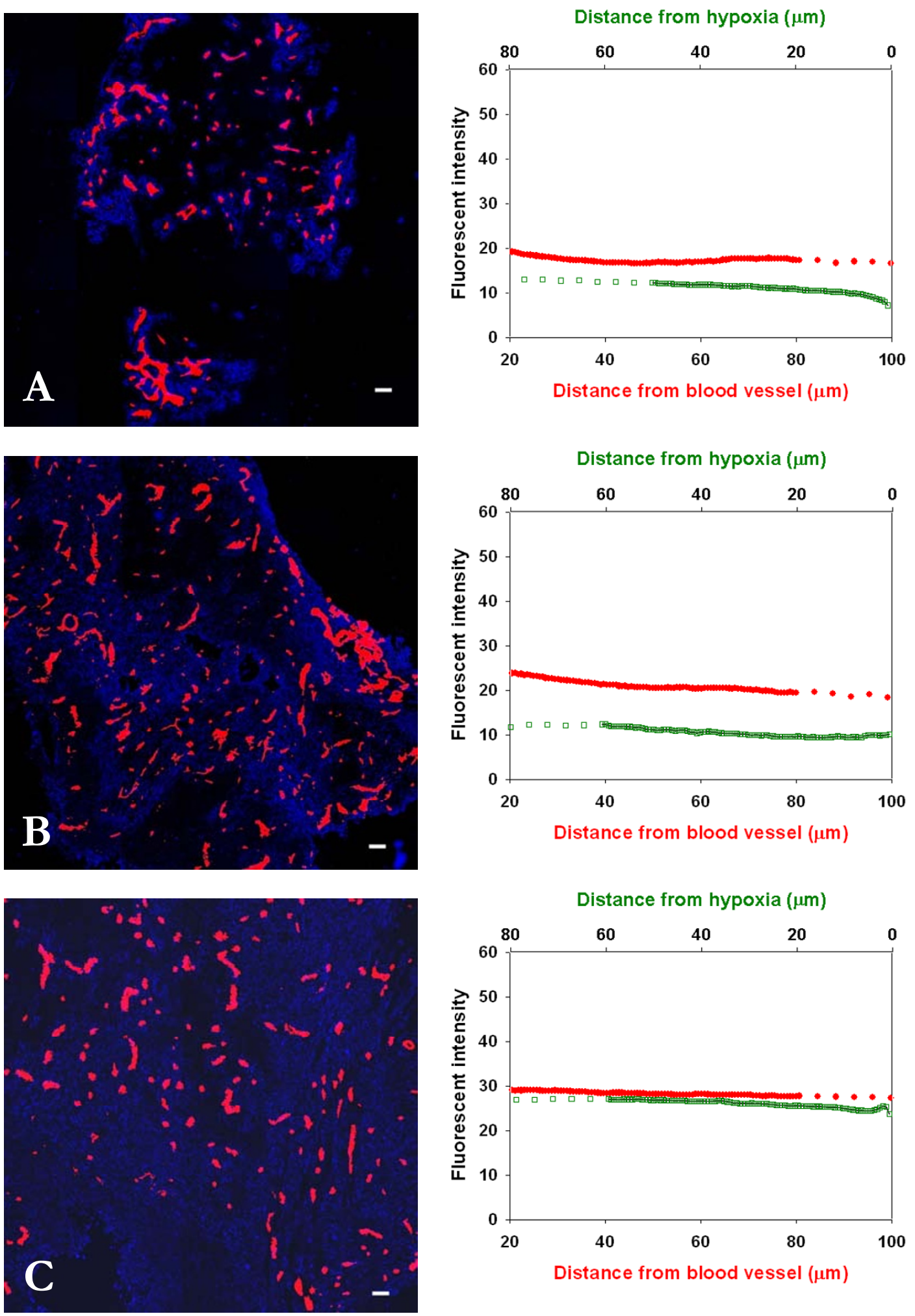

Figure 5 Time response distribution of trastuzumab in relation to blood vessels and regions of hypoxia in 231-H2N xenografts. Left panels show the distribution of trastuzumab (blue) in relation to blood vessels (red) in MDA-MB-231 breast cancer xenografts transfected with ErbB2 (231$\mathrm{H} 2 \mathrm{~N}$ ) at (A) $30 \mathrm{~min}$, (B) $4 \mathrm{~h}$ and (C) $24 \mathrm{~h}$ after i.v. injection of $0.3 \mathrm{mg}$ trastuzumab. In right panels staining intensity due to trastuzumab is plotted against distance to the blood vessel in red and distance to region of hypoxia in green. Scale bar $=100 \mu \mathrm{m}$. 
tion of trastuzumab was reported to lead to serum levels of about $5 \mathrm{ng} / \mathrm{ml}$ at 6-24 hours after i.p injection of a single low dose of $0.3 \mathrm{mg} / \mathrm{kg}$ into mice [43]; if pharmacokinetics were linear this would imply doses of $\sim 15 \mathrm{mg} /$ mouse to achieve levels of $10 \mathrm{ug} / \mathrm{ml}$ in serum, but it seems unlikely that pharmacokinetics of the two antibodies would differ by such a large amount.

Several other investigators have studied the distribution of various antibodies, or antibody fragments, in tumors. Their results depend on changes in blood flow [44] the affinity of the antibodies for their targets, but in general these authors have reported problems of heterogeneity of distribution at various times after their administration [45-48]. We were able to identify two other studies of the distribution of trastuzumab (but none of cetuximab) in solid tumors. Dennis et al used intravital microscopy to detect trastuzumab, conjugated to fluorescein isothiocyanate (FITC), in relation to blood vessels of MMTV/HER2 transgenic mice (expressing high levels of ErbB2) that were constrained to grow in a transparent window chamber; they reported perivascular localization of trastuzumab at 24 hours after injection of $10 \mathrm{mg} / \mathrm{kg}$ (about $0.25 \mathrm{mg} /$ mouse) [49]. Their study suggests poorer (or slower) distribution of trastuzumab than the one reported here; a possible reason is higher expression of ErbB2 in the MMTV/HER tumors as compared to the 231-H2N xenografts investigated in our study. Baker et al used similar methods to our own, and investigated timedependent distributions of trastuzumab in xenografts (that did or did not express ErbB2) after i.p. injection doses in the range of $4-20 \mathrm{mg} / \mathrm{kg}$ (about $0.1-0.5 \mathrm{mg} /$ mouse) [50]. They found perivascular distribution of drug at $3 \mathrm{~h}$, and that tumor margins reached saturation with trastuzumab more rapidly than the (poorly-vascularized) interior. Drug distribution became more uniform at $24 \mathrm{~h}$ as compared to $8 \mathrm{~h}$ after injection of $4 \mathrm{mg} / \mathrm{kg}$, but some heterogeneity of trastuzumab distribution was observed in the tumor under all conditions; this is consistent with our finding of poor drug uptake in hypoxic tumor regions.

\section{Conclusions}

Limited distribution of anticancer drugs (including molecular targeted agents) to cells within human tumors is an important mechanism that may lead to clinical drug resistance. The present study suggests that while distribution of cetuximab and trastuzumab within tumor tissue is time and dose-dependent, the sustained concentrations achieved by repeated dosing in patients is likely to achieve relatively uniform concentration within most areas of tumors, although there is poor drug binding in hypoxic regions. Thus the presence of hypoxia may be associated with resistance to these targeted agents, as well as to radiotherapy and chemotherapy.
Competing interests

The authors declare that they have no competing interests.

\section{Authors' contributions}

$\mathrm{CL}$ designed and performed all the experiments and drafted the manuscript. IT conceived of the study, obtained funding for it and participated in its design and coordination and drafted the manuscript. Both authors read and approved the final manuscript.

\section{Acknowledgements}

Supported by a research grant from the Canadian Institutes for Health Research (MOP 89762). We thank Dr Licun Wu for technical support.

\section{Author Details}

Divisions of Applied Molecular Oncology and Medical Oncology and Hematology Princess Margaret Hospital and University of Toronto, Toronto, ON, Canada

Received: 17 July 2009 Accepted: 3 June 2010

Published: 3 June 2010

References

1. Roskoski R Jr: The ErbB/HER receptor protein-tyrosine kinases and cancer. Biochemical and biophysical research communications 2004, 319(1):1-11

2. Weiss A, Schlessinger J: Switching signals on or off by receptor dimerization. Cell 1998, 94(3):277-280.

3. DiGiovanna MP, Stern DF, Edgerton SM, Whalen SG, Moore D, Thor AD Relationship of epidermal growth factor receptor expression to ErbB-2 signaling activity and prognosis in breast cancer patients. J Clin Oncol 2005, 23(6):1152-1160

4. O'Dwyer PJ, Benson AB: Epidermal growth factor receptor-targeted therapy in colorectal cancer. Seminars in oncology 2002, 29(5 Suppl 14):10-17.

5. Herbst RS, Hong WK: IMC-C225, an anti-epidermal growth factor receptor monoclonal antibody for treatment of head and neck cancer. Seminars in oncology 2002, 29(5 Suppl 14):18-30.

6. Lager DJ, Slagel DD, Palechek PL: The expression of epidermal growth factor receptor and transforming growth factor alpha in renal cell carcinoma. Mod Pathol 1994, 7(5):544-548

7. Berger MS, Gullick WJ, Greenfield C, Evans S, Addis BJ, Waterfield MD: Epidermal growth factor receptors in lung tumours. The Journal of pathology 1987, 152(4):297-307.

8. Hirsch FR, Scagliotti GV, Langer CJ, Varella-Garcia M, Franklin WA Epidermal growth factor family of receptors in preneoplasia and lung cancer: perspectives for targeted therapies. Lung cancer (Amsterdam, Netherlands) 2003, 41(Suppl 1):S29-42.

9. Xiong $\mathrm{HQ}$, Abbruzzese JL: Epidermal growth factor receptor-targeted therapy for pancreatic cancer. Seminars in oncology 2002, 29(5 Suppl 14):31-37.

10. Di Lorenzo G, Tortora G, D'Armiento FP, De Rosa G, Staibano S, Autorino R, D'Armiento M, De Laurentiis M, De Placido S, Catalano G, et al:: Expression of epidermal growth factor receptor correlates with disease relapse and progression to androgen-independence in human prostate cancer. Clin Cancer Res 2002, 8(11):3438-3444.

11. Itakura Y, Sasano H, Shiga C, Furukawa Y, Shiga K, Mori S, Nagura H: Epidermal growth factor receptor overexpression in esophageal carcinoma. An immunohistochemical study correlated with clinicopathologic findings and DNA amplification. Cancer 1994 74(3):795-804

12. Salomon DS, Brandt R, Ciardiello F, Normanno N: Epidermal growth factor-related peptides and their receptors in human malignancies. Critical reviews in oncology/hematology 1995, 19(3):183-232.

13. Goldberg RM: Cetuximab. Nature reviews 2005:S10-11.

14. Goldstein NI, Prewett M, Zuklys K, Rockwell P, Mendelsohn J: Biological efficacy of a chimeric antibody to the epidermal growth factor receptor in a human tumor xenograft model. Clin Cancer Res 1995 1(11):1311-1318.

15. Harris M: Monoclonal antibodies as therapeutic agents for cancer. The lancet oncology 2004, 5(5):292-302 
16. Sato JD, Kawamoto T, Le AD, Mendelsohn J, Polikoff J, Sato GH: Biological effects in vitro of monoclonal antibodies to human epidermal growth factor receptors. Molecular biology \& medicine 1983, 1(5):511-529.

17. Leyland-Jones B: Trastuzumab: hopes and realities. The lancet oncology 2002, 3(3):137-144

18. Herbst RS, Shin DM: Monoclonal antibodies to target epidermal growth factor receptor-positive tumors: a new paradigm for cancer therapy. Cancer 2002, 94(5):1593-1611.

19. Mendelsohn J: Epidermal growth factor receptor inhibition by a monoclonal antibody as anticancer therapy. Clin Cancer Res 1997, 3(12 Pt 2):2703-2707.

20. Molina MA, Codony-Servat J, Albanell J, Rojo F, Arribas J, Baselga J: Trastuzumab (herceptin), a humanized anti-Her2 receptor monoclonal antibody, inhibits basal and activated Her2 ectodomain cleavage in breast cancer cells. Cancer research 2001, 61(12):4744-4749.

21. Cunningham D, Humblet $Y$, Siena S, Khayat D, Bleiberg H, Santoro A, Bets D, Mueser M, Harstrick A, Verslype C, et al:: Cetuximab monotherapy and cetuximab plus irinotecan in irinotecan-refractory metastatic colorectal cancer. The New England journal of medicine 2004, 351(4):337-345.

22. Hudis CA: Trastuzumab--mechanism of action and use in clinical practice. The New England journal of medicine 2007, 357(1):39-51.

23. Minchinton Al, Tannock IF: Drug penetration in solid tumours. Nat Rev Cancer 2006, 6(8):583-592.

24. Primeau AJ, Rendon A, Hedley D, Lilge L, Tannock IF: The distribution of the anticancer drug Doxorubicin in relation to blood vessels in solid tumors. Clin Cancer Res 2005, 11(24 Pt 1):8782-8788.

25. Tredan O, Galmarini CM, Patel K, Tannock IF: Drug resistance and the solid tumor microenvironment. Journal of the National Cancer Institute 2007, 99(19):1441-1454

26. Jain RK: Transport of molecules in the tumor interstitium: a review. Cancer research 1987, 47(12):3039-3051.

27. Jain RK: Barriers to drug delivery in solid tumors. Scientific American 1994, 271(1):58-65.

28. Thurber GM, Schmidt MM, Wittrup KD: Factors determining antibody distribution in tumors. Trends in pharmacological sciences 2008, 29(2):57-61.

29. Evans SM, Hahn S, Pook DR, Jenkins WT, Chalian AA, Zhang P, Stevens C, Weber R, Weinstein G, Benjamin I, et al:: Detection of hypoxia in human squamous cell carcinoma by EF5 binding. Cancer research 2000 , 60(7):2018-2024.

30. Lord EM, Harwell L, Koch CJ: Detection of hypoxic cells by monoclonal antibody recognizing 2-nitroimidazole adducts. Cancer research 1993 53(23):5721-5726.

31. du Manoir JM, Francia G, Man S, Mossoba M, Medin JA, Viloria-Petit A, Hicklin DJ, Emmenegger U, Kerbel RS: Strategies for delaying or treating in vivo acquired resistance to trastuzumab in human breast cancer xenografts. Clin Cancer Res 2006, 12(3 Pt 1):904-916.

32. Joensuu H, Kellokumpu-Lehtinen PL, Bono P, Alanko T, Kataja V, Asola R, Utriainen T, Kokko R, Hemminki A, Tarkkanen M, et al: Adjuvant docetaxel or vinorelbine with or without trastuzumab for breast cancer. The New England journal of medicine 2006, 354(8):809-820.

33. Piccart-Gebhart MJ, Procter M, Leyland-Jones B, Goldhirsch A, Untch M, Smith I, Gianni L, Baselga J, Bell R, Jackisch C, et al:: Trastuzumab after adjuvant chemotherapy in HER2-positive breast cancer. The New England journal of medicine 2005, 353(16):1659-1672

34. Romond EH, Perez EA, Bryant J, Suman VJ, Geyer CE Jr, Davidson NE, TanChiu E, Martino S, Paik S, Kaufman PA, et al:: Trastuzumab plus adjuvant chemotherapy for operable HER2-positive breast cancer. The New England journal of medicine 2005, 353(16):1673-1684.

35. Sutherland R, Buchegger F, Schreyer M, Vacca A, Mach JP: Penetration and binding of radiolabeled anti-carcinoembryonic antigen monoclonal antibodies and their antigen binding fragments in human colon multicellular tumor spheroids. Cancer research 1987, 47(6):1627-1633.

36. Gustafson DL, Rastatter JC, Colombo T, Long ME: Doxorubicin pharmacokinetics: Macromolecule binding, metabolism, and excretion in the context of a physiologic model. Journal of pharmaceutical sciences 2002, 91(6):1488-1501.

37. Bruno R, Washington CB, Lu JF, Lieberman G, Banken L, Klein P: Population pharmacokinetics of trastuzumab in patients with HER2+ metastatic breast cancer. Cancer Chemother Pharmacol 2005 56(4):361-369

38. Fracasso PM, Burris $H$, Arquette MA, Govindan $R$, Gao F, Wright LP, Goodner SA, Greco FA, Jones SF, Willcut N, et al:: A phase 1 escalating single-dose and weekly fixed-dose study of cetuximab: pharmacokinetic and pharmacodynamic rationale for dosing. Clin Cancer Res 2007, 13(3):986-993.

39. Luo FR, Yang Z, Dong H, Camuso A, McGlinchey K, Fager K, Flefleh C, Kan D, Inigo I, Castaneda S, et al.: Correlation of pharmacokinetics with the antitumor activity of Cetuximab in nude mice bearing the GEO human colon carcinoma xenograft. Cancer Chemother Pharmacol 2005, 56(5):455-464

40. Stemmler HJ, Schmitt M, Willems A, Bernhard H, Harbeck N, Heinemann V: Ratio of trastuzumab levels in serum and cerebrospinal fluid is altered in HER2-positive breast cancer patients with brain metastases and impairment of blood-brain barrier. Anticancer Drugs 2007, 18(1):23-28.

41. Tan AR, Moore DF, Hidalgo M, Doroshow JH, Poplin EA, Goodin S, Mauro $D$, Rubin EH: Pharmacokinetics of cetuximab after administration of escalating single dosing and weekly fixed dosing in patients with solid tumors. Clin Cancer Res 2006, 12(21):6517-6522.

42. Tokuda Y, Watanabe T, Omuro Y, Ando M, Katsumata N, Okumura A, Ohta $M$, Fujii $H$, Sasaki $Y$, Niwa T, et al:: Dose escalation and pharmacokinetic study of a humanized anti-HER2 monoclonal antibody in patients with HER2/neu-overexpressing metastatic breast cancer. Br J Cancer 1999, 81(8):1419-1425.

43. Waterhouse DN, Denyssevych T, Hudon N, Chia S, Gelmon KA, Bally MB: Trastuzumab and liposomal Doxorubicin in the treatment of mcf-7 xenograft tumor-bearing mice: combination does not affect drug serum levels. Pharm Res 2005, 22(6):915-922

44. Blumenthal RD, Osorio L, Ochakovskaya R, Ying Z, Goldenberg DM: Regulation of tumour drug delivery by blood flow chronobiology. Eur J Cancer 2000, 36(14):1876-1884.

45. Adams GP, Schier R, McCall AM, Simmons HH, Horak EM, Alpaugh RK, Marks JD, Weiner LM: High affinity restricts the localization and tumor penetration of single-chain fv antibody molecules. Cancer research 2001, 61(12):4750-4755

46. Jones PL, Gallagher BM, Sands H: Autoradiographic analysis of monoclonal antibody distribution in human colon and breast tumor xenografts. Cancer Immunol Immunother 1986, 22(2):139-143.

47. Saga T, Neumann RD, Heya T, Sato J, Kinuya S, Le N, Paik CH, Weinstein JN: Targeting cancer micrometastases with monoclonal antibodies: a binding-site barrier. Proceedings of the National Academy of Sciences of the United States of America 1995, 92(19):8999-9003.

48. Steffens MG, Oosterwijk-Wakka JC, Zegwaart-Hagemeier NE, Boerman OC, Debruyne FM, Corstens FH, Oosterwijk E: Immunohistochemical analysis of tumor antigen saturation following injection of monoclonal antibody G250. Anticancer research 1999, 19(2A):1197-1200.

49. Dennis MS, Jin H, Dugger D, Yang R, McFarland L, Ogasawara A, Williams S, Cole MJ, Ross S, Schwall R: Imaging tumors with an albumin-binding Fab, a novel tumor-targeting agent. Cancer research 2007 67(1):254-261.

50. Baker JH, Lindquist KE, Huxham LA, Kyle AH, Sy JT, Minchinton Al: Direct visualization of heterogeneous extravascular distribution of trastuzumab in human epidermal growth factor receptor type 2 overexpressing xenografts. Clin Cancer Res 2008, 14(7):2171-2179.

\section{Pre-publication history}

The pre-publication history for this paper can be accessed here: http://www.biomedcentral.com/1471-2407/10/255/prepub

doi: 10.1186/1471-2407-10-255

Cite this article as: Lee and Tannock, The distribution of the therapeutic monoclonal antibodies cetuximab and trastuzumab within solid tumors BMC Cancer 2010, 10:255 